\title{
Arriba durante la Transición española: el abandono de su función propagandística con respecto al Gobierno ${ }^{1}$
}

\author{
Jezabel MARTíNEZ FÁBREGAS \\ Universidad de Sevilla \\ jmartinez10@us.es \\ Lorena R. RoMero DomíngueZ \\ Universidad de Sevilla \\ lorenaromero@us.es
}

Recibido: 30 de mayo de 2014

Aceptado: 10 de octubre de 2014

\begin{abstract}
Resumen
Durante la transición española, se produjeron cambios políticos, sociales, ideológicos y periodísticos en el país que contribuyeron a que el diario Arriba, fundado por Falange Española y asimilado como órgano de propaganda por el régimen franquista durante la dictadura, evolucionara considerablemente. Pasó, así, gracias a la presencia de diferentes ideologías en su redacción, del apoyo al Gobierno, aún muy presente tras la muerte de Franco (noviembre de 1975), a la crítica hacia el mismo al fin de este período, el referéndum de la Constitución (diciembre de 1978).
\end{abstract}

Palabras clave: historia del periodismo; prensa franquista; prensa del Movimiento; diario Arriba; transición española

\section{Arriba during the Spanish Transition: the abandonment of its propaganda function with respect to the Government}

\begin{abstract}
During the Spanish transition, there were political, social and ideological, but also journalistic updates in the country, which caused the newspaper Arriba, founded by 'Falange Española' and assimilated as a propaganda organ by Franco's regime during the dictatorship, evolved during the Spanish transition. Due to the incoming ideologies in its newsroom, the newspaper went from supporting the government after Caudillo's death (November, 1975), to criticize it at the end of the period, during the referendum of the Constitution (December, 1978).
\end{abstract}

Key words: journalism history; francoism press; Movement press; newspaper Arriba; Spanish transition.

1 Este estudio se inserta en el Proyecto de Investigación "El papel de la prensa diaria en la transición democrática. Cobertura informativa y comportamiento político de diarios y periodistas", referencia CSO2012-36774, del Plan Nacional I+D 2013-2015 CSO 2012 36774, dirigido por el Catedrático Dr. Jaume Guillamet Lloveras (Universitat Pompeu Fabra). 


\section{Referencia normalizada}

Martínez Fábregas, J. y Romero Domínguez, L. R. (2014) Arriba durante la Transición Española: el abandono de su función propagandística con respecto al Gobierno. Historia y Comunicación Social. Vol. 19. Páginas 321-340.

Sumario: 1. Introducción y breve estado de la cuestión. 2. Metodología. 3. Resultados y discusión. 3.1. Durante el Gobierno Arias (1974-1976) 3.2. Durante el Gobierno Suárez (1976-1977) 3.3. Durante el Gobierno de la UCD (1977-1981) 4. Conclusiones. 5. Referencias bibliográficas.

\section{Introducción y breve estado de la cuestión}

La transición democrática es el proceso político por el que España pasa de un régimen dictatorial a una monarquía parlamentaria. Este cambio de régimen supuso modificaciones a nivel legislativo, económico, social, político y también periodístico en el país. Pero, ¿qué segmento temporal comprende esta "transición"? Muchos han sido los historiadores que han intentado dar respuesta a esta pregunta no exenta de cierta polémica y debate. Si bien la mayoría de ellos coinciden en su punto de inicio (la muerte de Franco), difieren en su punto final. Así, por un lado, Soto (1994: 110-111) sostiene que el punto final de la transición se sitúa en el referéndum de la Constitución, el 6 de diciembre de 1978.

Para el profesor Tusell (1991: 10-11), sin embargo, el proceso de transición democrática española culmina con la victoria del PSOE en las elecciones generales de 1982. Y, para Juan Pablo Fusi (1997: 44), con la llegada del país a la Comunidad Económica Europea (1986).

Sin embargo, en sentido estricto, la transición es el período durante el cual se producen los cambios legales y políticos que permiten el paso de un sistema dictatorial a uno democrático entre 1975 y 1978, siendo la muerte de Franco (20 de noviembre de 1975) su punto de inicio, y el referéndum de la Constitución (6 de diciembre de 1978) de fin (Guillamet, 2002).

En la presente investigación, este período histórico de 38 meses de duración ha sido abordado a través del diario Arriba, periódico de referencia del Movimiento Nacional. Fundado el 21 de marzo de 1935 por José Antonio Primo de Rivera, era el órgano de propaganda de Falange Española y de las JONS, por lo que en su cabecera lució el yugo y las flechas hasta 1977, fecha de disolución del Movimiento Nacional.

El diario tuvo dos épocas bien diferenciadas: durante la primera (1935-1936) solían trabajar en él los intérpretes más autorizados del pensamiento falangista. Sin embargo, el periódico situado en la calle Larra de Madrid, sufrió una primera suspensión que le obligó a cesar su edición en julio de 1935 por orden gubernativa tras la publicación de un artículo contra la CEDA (Confederación Española de Derechas Autónomas). Retomó su publicación en octubre de ese año, editándose hasta el 5 de marzo de 1936, cuando fue suspendido por el Gobierno del Frente Popular. Y rena- 
ció el 30 de marzo de 1939 tras la toma de Madrid. Entonces comienza su segunda época en la que estaba al servicio del régimen a través de su inclusión en la cadena de Prensa del Movimiento Nacional.

Durante este segundo período (1939-1979), la cabecera, que se había trasladado a la Avenida Generalísimo Franco $\mathrm{n}^{\circ} 142$, ocupando las instalaciones incautadas al diario madrileño El Sol (periódico liberal de La Papelera Española), se convierte en el diario de referencia del Movimiento.

Se editaba en formato berlinés ( $35 \times 42 \mathrm{~cm}$.), con tipografía times, en blanco y negro, reservando el color para la edición dominical. Para la elaboración de sus informaciones contaba con las agencias Logos, Cifra, Cifra Gráfica, Europa Press, EFE y Pyresa (la agencia de noticias del Movimiento). Sus páginas fueron, en esta segunda época, el canal que utilizó el régimen para difundir la "conciencia nacional" y la unidad territorial al servicio de la dictadura.

Este panorama, sin embargo, evolucionó de forma considerable durante la transición, si bien es cierto que nos encontramos aún en un estado autoritario (Guillamet, 2002) en el que las multas y sanciones contra los periodistas se mantendrán hasta, por lo menos, 1982 (Meneses, 2008).

De acuerdo con esta presentación del diario, nuestra intención es, por una parte, analizar la evolución ideológica que experimentó esta cabecera de titularidad estatal durante la transición. Y, por otro, desmitificarla como órgano de propaganda del Gobierno durante este lapso de tiempo. Tesis ésta que ha sido tradicionalmente sostenida por Montabes Pereira (1989), quien afirma que la prensa oficial mantuvo su función propagandística con respecto al Gobierno. Por ello, el mencionado autor concluye que no evolucionó en este sentido durante este período. En la misma línea, Alférez (1986) sostiene que las ideologías de los trabajadores de la prensa oficial nunca llegaban a las páginas de la misma, que se esmeraba en ser un órgano de propaganda del Gobierno durante este período, o al menos durante el turno de Arias en el poder (Redero y García, 1991). Se garantizaba así, según los autores, el mantenimiento de un discurso único y unificado propio de los órganos de propaganda (Postoutenko, 2010) en el que no caben posicionamientos contrarios al poder (Pineda, 2006).

Sin embargo, Castro Torres (2010) reconoce la existencia de distintos discursos dentro de la prensa oficial durante estos tres años, que le permitieron asumir su rol de agente político. Además, Peña Marín (1980) reconoce que, ya durante la dictadura, revistas como El Escorial (dirigida por Laín Entralgo y Dionisio Ridruejo) acogieron posicionamientos contrarios al régimen. Más allá va la profesora Meneses (2008), quien afirma que, durante la transición, la prensa oficial acogió distintas ideologías en sus páginas.

Fruto de este profundo debate sobre el verdadero proceder de la prensa oficial con respecto al Gobierno durante la transición española surge nuestra pregunta de investigación: ¿Continuó el diario Arriba siendo un órgano de propaganda del gobierno 
durante la transición española? Para dar respuesta a esta pregunta, partimos de las siguientes hipótesis formuladas a partir del método hipotético- deductivo:

- (H1): El diario nodriza del Movimiento (Arriba) acogió diferentes ideologías durante la transición que se tradujeron en diferentes discursos, a veces contrarios entre sí, sobre el Gobierno y su gestión de la transición.

- (H2): El diario de referencia del Movimiento evolucionó en su posicionamiento con respecto al Gobierno durante la transición.

- (H3): El diario Arriba abandona su función propagandística con respecto al Ejecutivo durante la transición asumiendo su rol de agente político activo.

Tomando como referencia estas hipótesis, los objetivos que han guiado la presente investigación son los siguientes:

- Demostrar la presencia de diferentes ideologías en el diario y la confluencia de distintos discursos con respecto al Gobierno y su gestión durante la transición española.

- Demostrar la evolución del posicionamiento que este periódico oficial tuvo con respecto al Gobierno durante este período.

- Demostrar la función de agente político del diario en el espectro periodístico español de la transición, adquirido a través del abandono de su función propagandística del Gobierno.

Una vez formulados las hipótesis y los objetivos de la presente investigación, procedemos a explicar la metodología que hemos aplicado a nuestro objeto de estudio.

\section{Metodología}

Para la elaboración de este trabajo, hemos utilizado, en primer lugar, el estudio basado en la biografía técnica que propone Casasús (1985) sobre el diario seleccionado. La ficha hemerográfica del periódico (re-elaborada sobre una propuesta del doctor Marcel Mauri, en su tesis doctoral) nos ha permitido realizar un estudio biográfico de la cabecera seleccionada, además de averiguar la inclinación ideológica (1) de los firmantes en este diario durante la transición, lo cual constituye una de las principales líneas de este trabajo.

Una vez analizada hemerográficamente la cabecera, procedemos al análisis de contenido cualitativo explícito, que consiste en un estudio sistemático de una muestra seleccionada de forma objetiva haciendo inferencias validas y confiables en función del contexto en el que los textos fueron producidos (Krippendorff, 1982). Y, para su análisis, nos hemos decantado por centrarnos en el contenido explícito o manifiesto 
que, según Landry (1991: 341), "remite a lo que es dicho o escrito explícitamente [...], vehicula la totalidad del significado".

Una vez seleccionado el método, para su aplicación es necesario recopilar la muestra siguiendo los principios que nos propone Krippendorf. En primer lugar, hemos de puntualizar que el análisis de las ediciones diarias del periódico entre noviembre de 1975 (muerte de Franco) y diciembre de 1978 (referéndum de la constitución) sería una muestra inabarcable para un estudio de este tipo (1.140 ediciones). Por ello hemos seleccionado 20 hitos históricos repartidos entre los tres gobiernos que transcurren durante la transición: Gobierno Arias (1974-1976, de inmovilismo político), Gobierno Suárez (1976-1977, de reforma pactada) y Gobierno de la UCD (19771981, gobierno del consenso) tal y como se puede comprobar en la tabla siguiente:

Tabla 1: Selección de fechas de seguimiento en base a los temas seleccionados.

\section{PERÍODO}

SELECCIÓN DE HITOS POR FECHAS

1- Noviembre de 1975: Desde el 18 de noviembre (fecha del tercer postoperatorio del caudillo, tras el que moriría el 20 de noviembre) hasta el 23 de noviembre (día después de la coronación de Juan Carlos I como Rey de España). De esta forma, abarcamos el pre y el post-mortem de Franco, así como el pre y el post- coronación de Juan Carlos I como Rey de España.

2- Marzo de 1976: Desde el 1 de marzo de 1976 (día en que empieza la huelga general) hasta el día 8 de marzo del mismo año (ataque contra las Fuerzas del Orden Público en el País Vasco) pasando por las muertes de Vitoria (3 de marzo de 1976).

3- Julio de 1976: Desde el 2 de julio de 1976, cuando Arias dimite, hasta el 8 de julio cuando la prensa presenta al nuevo Gabinete Suárez.

4- Diciembre de 1976: Según Lazarsfeld (1953), la propaganda política en períodos de elecciones electorales aumenta en la última semana de campaña para intentar ganar el voto de los más indecisos. Por esta razón, se ha seleccionado la semana previa a los comicios y los tres días posteriores a los mismos, ya que no sería hasta el 16 de junio por la tarde cuando se lanzaran los resultados definitivos.

5- Enero de 1977: Se ha seleccionado desde el 24 hasta el 31 de enero, porque durante esa semana se perpetraron ataques contra civiles (los abogados laboralistas en la Calle Atocha) y las Fuerzas de Orden Público.

1. Muerte de Franco (20/11/1975)

2. Coronación del Rey Juan Carlos I de Borbón $(22 / 11 / 1975)$

Recopilación: 18-23/11/1975

3. Huelga General (01/03/1976)

4. Muertes de Vitoria (03/03/1976)

Recopilación: 01-08/03/1976

5. Dimisión de Arias Navarro (02/07/1976)

6. Nombramiento de Adolfo Suárez como Presidente del Gobierno (05/07/1976)

Recopilación: 02-08/07/1976

7. Ley para la Reforma Política

Recopilación: 08- 18/12/1976

8. Crímenes de Atocha de Atocha $(24 / 01 / 1977)$

Recopilación 24-31/01/1977 


\begin{tabular}{|c|c|}
\hline $\begin{array}{l}\text { 6- Abril de 1977: Se ha seleccionado el período 01-14 } \\
\text { de abril, abarcando los hitos históricos seleccionados en } \\
\text { este período. De esta forma, se seguirán las opiniones } \\
\text { vertidas por los medios hasta dos días más tarde de pro- } \\
\text { ducirse el último de ellos: la convocatoria de elecciones } \\
\text { legislativas de junio de } 1977 \text {. }\end{array}$ & $\begin{array}{l}\text { 9. Disolución del Movimiento Nacional } \\
\text { (01/04/1977) } \\
\text { 10. Legalización del PCE (10/04/1977) } \\
\text { 11. Dimisión del almirante Pita da Veiga } \\
\text { (Ministro de Marina) (11/04/1977) } \\
\text { 12. Convocatoria electoral }(12 / 04 / 1977) \\
\text { Recopilación: } 01-14 / 04 / 1977\end{array}$ \\
\hline $\begin{array}{l}\text { 7- Junio de 1977: Para su selección se ha seguido el mis- } \\
\text { mo procedimiento que en el período } 4 .\end{array}$ & $\begin{array}{l}\text { 13. Elecciones legislativas }(15 / 06 / 1977) \\
\text { Recopilación: } 08-18 / 06 / 1977\end{array}$ \\
\hline $\begin{array}{l}\text { 8- Octubre de 1977: Se abordará el período comprendi- } \\
\text { do entre el } 13 \text { y el } 28 \text { de octubre. Es decir, dos días antes } \\
\text { de aprobarse la Ley de Amnistía hasta dos días después } \\
\text { de la firma de los Pactos de la Moncloa. }\end{array}$ & $\begin{array}{l}\text { 14. Amnistía General }(15 / 10 / 1977) \\
\text { 15. Pactos de la Moncloa }(25 / 10 / 1977) \\
\text { 16. Vuelta de Tarradellas }(23 / 10 / 1977) \\
\text { Recopilación: } 13-28 / 10 / 1977\end{array}$ \\
\hline $\begin{array}{l}\text { 9- Marzo de 1978: La selección de las ediciones se ha } \\
\text { realizado desde el día en que el PSOE abandona la po- } \\
\text { nencia (07/03/1978) hasta que se soluciona el problema } \\
\text { y vuelve a la Comisión (10/03/1978). }\end{array}$ & $\begin{array}{l}\text { 17. Crisis de la Ponencia Constitucional } \\
(07 / 03 / 1978) \\
\text { Recopilación: 07-10/03/1978 }\end{array}$ \\
\hline $\begin{array}{l}\text { 10. Noviembre de 1978: Únicamente se abordarán los } \\
\text { días } 1 \text { y } 2 \text { de noviembre, por ser el día en que se aprueba } \\
\text { el texto constitucional y la jornada posterior. Este último } \\
\text { se ha seleccionado porque la falta de inmediatez que } \\
\text { caracteriza a la prensa escrita permite abordar de forma } \\
\text { analítica en la siguiente edición el suceso en cuestión. }\end{array}$ & $\begin{array}{l}\text { 18. Aprobación de la Constitución } \\
(01 / 11 / 1978) \\
\text { Recopilación: } 01-02 / 11 / 1978\end{array}$ \\
\hline $\begin{array}{l}\text { 11. Noviembre de } 1978^{\mathrm{ii}} \text { : Se aborda desde que sale en } \\
\text { prensa por primera vez el intento de Golpe de Estado } \\
\text { hasta la comparecencia del Ministro de Defensa, Gutié- } \\
\text { rrez Mellado, ante el Presidente Suárez y ante las cá- } \\
\text { maras de Televisión Española, el día } 22 \text { de noviembre. }\end{array}$ & $\begin{array}{l}\text { 19. Operación Galaxia }(18 / 11 / 1978) \\
\text { Recopilación: } 18-22 / 12 / 1978\end{array}$ \\
\hline $\begin{array}{l}\text { 12. Diciembre de 1978: Para su selección se ha seguido } \\
\text { el mismo procedimiento que en los períodos } 4 \text { y } 7 \text {. }\end{array}$ & $\begin{array}{l}\text { 20. Referéndum Constitución Española } \\
(06 / 12 / 1978) \\
\text { Recopilación: 01- 08/12/1978 }\end{array}$ \\
\hline
\end{tabular}

Fuente: Elaboración propia.

Una vez recopilada la muestra, compuesta por 240 unidades de análisis (entre editoriales, artículos y columnas), es momento de diseñar las unidades de análisis sobre las que hemos aplicado nuestra metodología, y construir las categorías que nos permiten validar o refutar nuestras hipótesis para la consecución de nuestros objetivos.

Atendiendo a lo sostenido por Berelson (1952), quien considera las unidades de análisis como segmentos del contenido caracterizados para su ubicación dentro de categorías, hemos optado por los ítems (unidad total de material simbólico o textos periodísticos, en este caso), porque el método de esta investigación se ha aplicado sobre textos periodísticos, es decir, "una unidad total de material simbólico".

Teniendo en cuenta que nuestras hipótesis persiguen demostrar la existencia de distintos puntos de vista ideológicos dentro del diario Arriba, hemos optado por el 
análisis de los editoriales, artículos y columnas de opinión. Pero, ¿por qué estos géneros y no otros?

En primer lugar, hemos seleccionado los editoriales porque es el texto de opinión que goza de menor libertad a la hora de registrar tanto su lenguaje como su técnica y su estructura; es decir, "es un texto generalmente uniforme y de criterios más o menos fijos" (López Hidalgo, 2012: 35).

Por otro lado, para León Gross (1996: 145), el estudio del columnismo y el articulismo como fuente para analizar la prensa, "ha sido poco prolífico, hasta fechas recientes, por no estar encuadrado claramente en alguno de estos dos ámbitos (periodismo o literatura)"(2). Coincide con Villalobos (2010) quien afirma que, tradicionalmente, se ha estudiado la línea editorial de los periódicos para conocer el verdadero proceder del mismo con respecto a un tema concreto, ignorando el papel del columnismo y el articulismo en el asentamiento de un estado de opinión.

Sin embargo, para Martínez Albertos (1992: 382), las columnas constituyen unos espacios de tema libre destinados a escritores de prestigio y fama, con la única condición de que firmen sus textos. En este sentido, las columnas comparten el carácter de 'tema libre' con los artículos de opinión, de los que Martín Vivaldi (1993: 176) dice que son escritos "de muy vario y amplio contenido, de varia y muy diversa forma, en el que interpreta, valora o explica un hecho o una idea actuales de especial trascendencia, según la convicción del articulista”. Coincide con López Hidalgo (2012), quien asegura que las diferencias existentes entre lo sostenido por los editoriales y los artículos y las columnas de opinión pueden ser muy considerables, contradiciendo así a Abril Vargas (1999) quien afirma que estas diferencias no son más que meros matices.

Además, no sólo existen diferencias entre editoriales y columnas y artículos, sino también entre estos dos últimos. Así, para Vivaldi (1993), el columnista es un periodista que dispone de un espacio concreto y de forma asidua en el periódico, mientras que el articulista es un colaborador esporádico y experto en el tema concreto sobre el que escribe. Y esto a su vez contribuye a la presencia de distintos posicionamientos, al no tener relación de obediencia con respecto al medio (Pineda, 2006), erigiéndose así columnismo y articulismo de opinión en los garantes de la pluralidad de opinión en el diario (Borrat, 1989).

Tomando como referencias estas afirmaciones, la confluencia de distintos discursos sobre un mismo tema en el periódico puede suponer la ausencia de un discurso único y unificado dentro del mismo, al no seguir las columnas y los artículos los dictados del editorial. Y, por otro lado, atendiendo a la libertad para la selección del tema y el posicionamiento ideológico que rigen las opiniones de columnistas y articulistas (López Hidalgo, 2012), esta realidad podría suponer la confluencia de distintos posicionamientos con respecto al Gobierno por parte del periódico analizado. Este hecho invalidaría al diario nodriza como órgano de propaganda del Gobierno durante la transición tal y como sostenían Alférez (1986), Montabes Pereira (1989) y Redero y García (1991). 
Para finalizar estas consideraciones, Gómez Calderón (2004) y Villalobos (2010) demostraron que las piezas de opinión son una buena fuente para la investigación de un período histórico concreto. Ambos concluyeron que estos textos acogen diversos discursos sobre el mismo tema, dotando así al medio de pluralidad de opinión. Y ésta es una de las hipótesis de nuestro trabajo. Por lo tanto, los textos de opinión se perfilan como los garantes de cierta pluralidad ideológica en el diario Arriba. Y, por ende, es en ellos donde podemos encontrar, si las hay, diferentes posicionamientos con respecto al Gobierno durante la transición.

Una vez definidas las unidades de análisis, hemos de diseñar las categorías para la validación o refutación de nuestras hipótesis.

Según Berelson (1952), por categoría debe entenderse un concepto genérico que agrupa las proposiciones de varias unidades de registro. Coincide con Krippendorff (1982) en afirmar que las categorías son los niveles en los que se clasifican las unidades de análisis. Y de los posibles tipos que propone el autor, nosotros nos centraremos en la tipología de dirección, encaminada a determinar la validez de nuestras hipótesis Esta modalidad se ha construido según el modelo cerrado que proponen Berelson (1952) y Krippendorff (1982), en el cual las categorías se determinan con anterioridad al análisis y tienen como objetivo la verificación de una o varias hipótesis. Por lo tanto, las categorías construidas para el presente trabajo de acuerdo con nuestras hipótesis son:

1. Posicionamiento Positivo: apoyo explícito al Gobierno.

2. Posicionamiento Neutro: Sin enjuiciar la gestión gubernamental.

3. Posicionamiento Negativo: críticas a la labor del Ejecutivo.

Hasta ahora, la mayoría de los estudios han concluido que la prensa oficial mantenía un posicionamiento positivo con respecto al Gobierno (Alférez (1986), Montabes Pereira (1989) y Redero y García, 1991). La demostración de la presencia de los otros dos discursos constituiría la prueba de la confluencia de distintos comportamientos con respecto al Gobierno, lo que contradice la teoría de que la prensa, en un régimen autoritario, no puede tener un discurso contrario al poder que la ha creado y, por tanto, demostraría que el diario Arriba no fue un órgano de propaganda del Gobierno durante la transición.

\section{Resultados y discusión}

En el órgano no oficial de toma de decisiones del diario Arriba (el periódico no contaba con Consejo Editorial, ya que tradicionalmente las decisiones que lo regían venían desde la Delegación Nacional de Prensa y, posteriormente, del Ministerio de Información) coincidieron ucedistas, socialistas y falangistas, como se puede ver a continuación: 
Tabla 2: Composición del Consejo editorial /órgano de toma de decisiones de Arriba durante la transición (1975-1978).

\begin{tabular}{|l|l|l|l|}
\hline \multicolumn{4}{|c|}{ CONSEJO EDITORIAL } \\
\hline Nombre completo & Cargo & Relación con el medio & $\begin{array}{l}\text { Militancia o desarrollo } \\
\text { profesional (9) }\end{array}$ \\
\hline Alejo Jesús García Ortega & Subdirector & Propio $^{3}(1975-1976)$ & -- \\
\hline José A. Gurriarán López & Subdirector & Propio (1975-1976) & PSOE $^{4}$ \\
\hline Ángel del Río & Subdirector & Propio (1977-1979) & -- \\
\hline Francisco Muro de Íscar & Subdirector & Propio (1976-1979) & -- \\
\hline Enrique de Aguinaga López & $\begin{array}{l}\text { Jefe de Sección de 'Hue- } \\
\text { co Grabado' }\end{array}$ & Propio (1962-1979) & -- \\
\hline Pedro Rodríguez & Subdirector & Propio (1976-1979) & Falangista \\
\hline Mariano del Mazo Zugazagoitia & Redactor jefe & Propio (1975-1979) & -- \\
\hline Fernando Lanzaco Bonilla & Subdirector & Propio (1977-1979) & -- \\
\hline José Má. Menéndez Ríos & Redactor jefe & Propio (1974-1977) & -- \\
\hline Fernando Ónega López & Subdirector & Propio (1976-1979) & UCD \\
\hline Chelo Escobar Castro & Jefa de sección & Propio (1975-1979) & -- \\
\hline José Cavero Jañez & Redactor Jefe & Propio (1976-1979) & Pro UCD $^{7}$ \\
\hline Félix Ortega Muñoz & Subdirector & Propio (1976-1979) & -- \\
\hline César de Navascués & Redactor Jefe & Propio (1975-1977) & -- \\
\hline Jordi Casasampere Gibsert & Redactor Jefe & Propio (1977-1979) & -- \\
\hline Francisco Sáez González & Subdirector & Propio (1975-1979) & -- \\
\hline Manuel Roca Basanta & Jefe de Sección & Propio (1977-1979) & -- \\
\hline Luis Carrillo & Jefe de Sección & Propio (1975-1979) & -- \\
\hline Valentín Martín Martín & Jefe de Sección & Propio (1975-1979) & -- \\
\hline Juan Blanco & Redactor Jefe & Propio (1974-1979) & Falangista \\
\hline
\end{tabular}

Fuente: Elaboración propia.

Tras la muerte de Franco (noviembre de 1975) se observa una entrada de personal que no formaba parte del diario antes de la caída del régimen. Esto supone una renovación del órgano de decisiones del periódico y, por lo tanto, una evolución del mismo, al contrario de lo que sostenía Montabes Pereira (1989). De hecho, la entrada de estas personas, con diferentes ideologías cada uno de ellos, supondrá, como veremos más adelante, la presencia de distintos posicionamientos con respecto al Ejecutivo y su gestión durante la transición.

De esta forma, en la toma de decisiones del diario intervenían distintos puntos de vista ideológico, lo que constituía la confluencia de diferentes prismas desde los que interpretar la realidad que acontecía en España durante la transición. Además, la convivencia de estos distintos enfoques ideológicos en la cúspide del diario facilita la presencia de pluralidad de opiniones en sus páginas de opinión (Borrat, 1989). Y es que, tal y como sostiene Pineda (2006), el trabajador propio debe obediencia a los intereses del medio en el que trabaja. Sin embargo, esta relación de obediencia es hartamente difusa cuando en el propio órgano de poder del periódico confluyen distintos puntos de vista, lo que puede propiciar que estos diferentes prismas desde 
los que analizar la realidad se transfieran al papel traduciéndose en diferentes posicionamientos con respecto al Gobierno y su gestión.

Y, precisamente, gracias a este ambiente tan propicio dentro del propio diario, las distintas ideologías se materializaron en las páginas de opinión del periódico. Así lo demuestra el análisis de contenido aplicado a la muestra seleccionada (véase tabla 3, en Anexos), que nos desvela la presencia de una gran afinidad entre la línea editorial y el Gobierno, alcanzando un total del 78,47\%, pero también constata que el $21,24 \%$ de los textos publicados se posicionaron en tono neutro y negativo con respecto a la gestión gubernamental, como se puede comprobar en la siguiente tabla:

Tabla 3: Posicionamiento en torno al Gobierno en cada hito histórico analizado en porcentajes.

\begin{tabular}{|c|c|c|c|c|c|c|c|c|c|}
\hline \multirow{2}{*}{ HITOS } & \multicolumn{3}{|c|}{ LÍNEA EDITORIAL } & \multicolumn{3}{|c|}{ COLUMNAS } & \multicolumn{3}{|c|}{ ARTÍCULOS DE OPINIÓN } \\
\hline & POS & $\mathbf{0}$ & NEG & POS & $\mathbf{0}$ & NEG & POS & $\mathbf{0}$ & NEG \\
\hline $\begin{array}{l}\text { Muerte De } \\
\text { Franco }\end{array}$ & $\begin{array}{c}2 \\
(100 \%)\end{array}$ & $\begin{array}{c}0 \\
(0 \%)\end{array}$ & $\begin{array}{c}0 \\
(0 \%)\end{array}$ & $\begin{array}{c}4 \\
(80 \%)\end{array}$ & $\begin{array}{c}1 \\
(20 \%)\end{array}$ & $\begin{array}{c}0 \\
(0 \%)\end{array}$ & $\begin{array}{c}2 \\
(100 \%)\end{array}$ & $\begin{array}{c}0 \\
(0 \%)\end{array}$ & $\begin{array}{c}0 \\
(0 \%)\end{array}$ \\
\hline $\begin{array}{l}\text { Instauración } \\
\text { Monarquía }\end{array}$ & $\begin{array}{c}1 \\
(100 \%)\end{array}$ & $\begin{array}{c}0 \\
(0 \%) \\
\end{array}$ & $\begin{array}{c}0 \\
(0 \%) \\
\end{array}$ & $\begin{array}{c}1 \\
(25 \%) \\
\end{array}$ & $\begin{array}{c}3 \\
(75 \%) \\
\end{array}$ & $\begin{array}{c}0 \\
(0 \%) \\
\end{array}$ & $\begin{array}{c}0 \\
(0 \%)\end{array}$ & $\begin{array}{c}0 \\
(0 \%) \\
\end{array}$ & $\begin{array}{c}0 \\
(0 \%)\end{array}$ \\
\hline Huelga general & $\begin{array}{c}1 \\
(50 \%) \\
\end{array}$ & $\begin{array}{c}1 \\
(50 \%) \\
\end{array}$ & $\begin{array}{c}0 \\
(0 \%) \\
\end{array}$ & $\begin{array}{c}1 \\
(25 \%) \\
\end{array}$ & $\begin{array}{c}1 \\
(25 \%) \\
\end{array}$ & $\begin{array}{c}2 \\
(50 \%) \\
\end{array}$ & $\begin{array}{c}2 \\
(100 \%)\end{array}$ & $\begin{array}{c}0 \\
(0 \%) \\
\end{array}$ & $\begin{array}{c}0 \\
(0 \%) \\
\end{array}$ \\
\hline $\begin{array}{l}\text { muertes de } \\
\text { Vitoria }\end{array}$ & $\begin{array}{c}2 \\
(100 \%)\end{array}$ & $\begin{array}{c}0 \\
(0 \%)\end{array}$ & $\begin{array}{c}0 \\
(0 \%)\end{array}$ & $\begin{array}{c}2 \\
(100 \%)\end{array}$ & $\begin{array}{c}0 \\
(0 \%)\end{array}$ & $\begin{array}{c}0 \\
(0 \%)\end{array}$ & $\begin{array}{c}1 \\
(100 \%)\end{array}$ & $\begin{array}{c}0 \\
(0 \%)\end{array}$ & $\begin{array}{c}0 \\
(0 \%)\end{array}$ \\
\hline Dimisión Arias & $\begin{array}{c}2 \\
(100 \%)\end{array}$ & $\begin{array}{c}0 \\
(0 \%) \\
\end{array}$ & $\begin{array}{c}0 \\
(0 \%) \\
\end{array}$ & $\begin{array}{c}1 \\
(100 \%)\end{array}$ & $\begin{array}{c}0 \\
(0 \%) \\
\end{array}$ & $\begin{array}{c}0 \\
(0 \%) \\
\end{array}$ & $\begin{array}{c}1 \\
(100 \%)\end{array}$ & $\begin{array}{c}0 \\
(0 \%) \\
\end{array}$ & $\begin{array}{c}0 \\
(0 \%) \\
\end{array}$ \\
\hline $\begin{array}{l}\text { Nombramiento } \\
\text { Suárez }\end{array}$ & $\begin{array}{c}5 \\
(100 \%)\end{array}$ & $\begin{array}{c}0 \\
(0 \%)\end{array}$ & $\begin{array}{c}0 \\
(0 \%)\end{array}$ & $\begin{array}{c}4 \\
(100 \%)\end{array}$ & $\begin{array}{c}0 \\
(0 \%)\end{array}$ & $\begin{array}{c}0 \\
(0 \%)\end{array}$ & $\begin{array}{c}2 \\
(100 \%)\end{array}$ & $\begin{array}{c}0 \\
(0 \%)\end{array}$ & $\begin{array}{c}0 \\
(0 \%)\end{array}$ \\
\hline LRP & $\begin{array}{c}6 \\
(100 \%) \\
\end{array}$ & $\begin{array}{c}0 \\
(0 \%) \\
\end{array}$ & $\begin{array}{c}0 \\
(0 \%) \\
\end{array}$ & $\begin{array}{c}2 \\
(33.33 \%) \\
\end{array}$ & $\begin{array}{c}3 \\
(50 \%) \\
\end{array}$ & $\begin{array}{c}1 \\
(16.66 \%) \\
\end{array}$ & $\begin{array}{c}3 \\
(50 \%) \\
\end{array}$ & $\begin{array}{c}1 \\
(16,66 \%) \\
\end{array}$ & $\begin{array}{c}2 \\
(33.33 \%) \\
\end{array}$ \\
\hline $\begin{array}{l}\text { Crímenes De } \\
\text { Atocha }\end{array}$ & $\begin{array}{c}8 \\
(100 \%) \\
\end{array}$ & $\begin{array}{c}0 \\
(0 \%) \\
\end{array}$ & $\begin{array}{c}0 \\
(0 \%) \\
\end{array}$ & $\begin{array}{c}5 \\
(55.55 \%) \\
\end{array}$ & $\begin{array}{c}2 \\
(22.22 \%) \\
\end{array}$ & $\begin{array}{c}2 \\
(22,22 \%) \\
\end{array}$ & $\begin{array}{c}1 \\
(33.33 \%) \\
\end{array}$ & $\begin{array}{c}2 \\
(66.66 \%) \\
\end{array}$ & $\begin{array}{c}0 \\
(0 \%) \\
\end{array}$ \\
\hline $\begin{array}{l}\text { Disolución } \\
\text { Movimiento } \\
\text { Nacional }\end{array}$ & $\begin{array}{c}3 \\
(100 \%)\end{array}$ & $\begin{array}{c}0 \\
(0 \%)\end{array}$ & $\begin{array}{c}0 \\
(0 \%)\end{array}$ & $\begin{array}{c}0 \\
(0 \%)\end{array}$ & $\begin{array}{c}0 \\
(0 \%)\end{array}$ & $\begin{array}{c}0 \\
(0 \%)\end{array}$ & $\begin{array}{c}0 \\
(0 \%)\end{array}$ & $\begin{array}{c}0 \\
(0 \%)\end{array}$ & $\begin{array}{c}0 \\
(0 \%)\end{array}$ \\
\hline $\begin{array}{l}\text { Legalización } \\
\text { PCE }\end{array}$ & $\begin{array}{c}3 \\
(100 \%) \\
\end{array}$ & $\begin{array}{c}0 \\
(0 \%) \\
\end{array}$ & $\begin{array}{c}0 \\
(0 \%) \\
\end{array}$ & $\begin{array}{c}2 \\
(50 \%) \\
\end{array}$ & $\begin{array}{c}1 \\
(25 \%) \\
\end{array}$ & $\begin{array}{c}1 \\
(25 \%) \\
\end{array}$ & $\begin{array}{c}1 \\
(100 \%) \\
\end{array}$ & $\begin{array}{c}0 \\
(0 \%) \\
\end{array}$ & $\begin{array}{c}0 \\
(0 \%) \\
\end{array}$ \\
\hline $\begin{array}{l}\text { Dimisión Pita da } \\
\text { Veiga }\end{array}$ & $\begin{array}{c}1 \\
(100 \%)\end{array}$ & $\begin{array}{c}0 \\
(0 \%)\end{array}$ & $\begin{array}{c}0 \\
(0 \%)\end{array}$ & $\begin{array}{c}1 \\
(100 \%)\end{array}$ & $\begin{array}{c}0 \\
(0 \%)\end{array}$ & $\begin{array}{c}0 \\
(0 \%)\end{array}$ & $\begin{array}{c}1 \\
(100 \%)\end{array}$ & $\begin{array}{c}0 \\
(0 \%)\end{array}$ & $\begin{array}{c}0 \\
(0 \%)\end{array}$ \\
\hline $\begin{array}{l}\text { Convocatoria } \\
\text { electoral }\end{array}$ & $\begin{array}{c}1 \\
(100 \%)\end{array}$ & $\begin{array}{c}0 \\
(0 \%) \\
\end{array}$ & $\begin{array}{c}0 \\
(0 \%) \\
\end{array}$ & $\begin{array}{c}2 \\
(100 \%)\end{array}$ & $\begin{array}{c}0 \\
(0 \%) \\
\end{array}$ & $\begin{array}{c}0 \\
(0 \%) \\
\end{array}$ & $\begin{array}{c}2 \\
(100 \%)\end{array}$ & $\begin{array}{c}0 \\
(0 \%) \\
\end{array}$ & $\begin{array}{c}0 \\
(0 \%) \\
\end{array}$ \\
\hline $\begin{array}{l}\text { Elecciones legis- } \\
\text { lativas }\end{array}$ & $\begin{array}{c}8 \\
(72.72 \%) \\
\end{array}$ & $\begin{array}{c}3 \\
(27.27 \%) \\
\end{array}$ & $\begin{array}{c}0 \\
(0 \%) \\
\end{array}$ & $\begin{array}{c}7 \\
(63.63 \%) \\
\end{array}$ & $\begin{array}{c}3 \\
(27.27 \%) \\
\end{array}$ & $\begin{array}{c}1 \\
(9.09 \%)\end{array}$ & $\begin{array}{c}7 \\
(58.13 \%) \\
\end{array}$ & $\begin{array}{c}3 \\
(25 \%) \\
\end{array}$ & $\begin{array}{c}2 \\
(16.66 \%)\end{array}$ \\
\hline Amnistía & $\begin{array}{c}1 \\
(50 \%) \\
\end{array}$ & $\begin{array}{c}1 \\
(50 \%) \\
\end{array}$ & $\begin{array}{c}0 \\
(0 \%) \\
\end{array}$ & $\begin{array}{c}2 \\
(50 \%) \\
\end{array}$ & $\begin{array}{c}2 \\
(50 \%) \\
\end{array}$ & $\begin{array}{c}0 \\
(0 \%) \\
\end{array}$ & $\begin{array}{c}0 \\
(0 \%) \\
\end{array}$ & $\begin{array}{c}0 \\
(0 \%) \\
\end{array}$ & $\begin{array}{c}0 \\
(0 \%) \\
\end{array}$ \\
\hline $\begin{array}{l}\text { Pactos de la } \\
\text { Moncloa }\end{array}$ & $\begin{array}{c}2 \\
(66.66 \%) \\
\end{array}$ & $\begin{array}{c}0 \\
(0 \%) \\
\end{array}$ & $\begin{array}{c}1 \\
(33.33 \%)\end{array}$ & $\begin{array}{c}0 \\
(0 \%)\end{array}$ & $\begin{array}{c}1 \\
(33.33 \%) \\
\end{array}$ & $\begin{array}{c}2 \\
(66.66 \%) \\
\end{array}$ & $\begin{array}{c}0 \\
(0 \%)\end{array}$ & $\begin{array}{c}1 \\
(25 \%)\end{array}$ & $\begin{array}{c}3 \\
(75 \%)\end{array}$ \\
\hline $\begin{array}{l}\text { Vuelta Tarra- } \\
\text { dellas }\end{array}$ & $\begin{array}{c}1 \\
(100 \%)\end{array}$ & $\begin{array}{c}0 \\
(0 \%)\end{array}$ & $\begin{array}{c}0 \\
(0 \%)\end{array}$ & $\begin{array}{c}0 \\
(0 \%)\end{array}$ & $\begin{array}{c}0 \\
(0 \%)\end{array}$ & $\begin{array}{c}0 \\
(0 \%)\end{array}$ & $\begin{array}{c}0 \\
(0 \%)\end{array}$ & $\begin{array}{c}0 \\
(0 \%)\end{array}$ & $\begin{array}{c}0 \\
(0 \%)\end{array}$ \\
\hline
\end{tabular}




\begin{tabular}{|c|c|c|c|c|c|c|c|c|c|}
\hline $\begin{array}{l}\text { Crisis ponencia } \\
\text { Constitucional }\end{array}$ & $\begin{array}{c}1 \\
(33.33 \%)\end{array}$ & $\begin{array}{c}2 \\
(66.66 \%)\end{array}$ & $\begin{array}{c}0 \\
(0 \%)\end{array}$ & $\begin{array}{c}1 \\
(50 \%)\end{array}$ & $\begin{array}{c}1 \\
(50 \%)\end{array}$ & $\begin{array}{c}0 \\
(0 \%)\end{array}$ & $\begin{array}{c}0 \\
(0 \%)\end{array}$ & $\begin{array}{c}0 \\
(0 \%)\end{array}$ & $\begin{array}{c}0 \\
(0 \%)\end{array}$ \\
\hline $\begin{array}{l}\text { Aprobación } \\
\text { Constitución }\end{array}$ & $\begin{array}{c}1 \\
(50 \%)\end{array}$ & $\begin{array}{c}0 \\
(0 \%)\end{array}$ & $\begin{array}{c}1 \\
(50 \%)\end{array}$ & $\begin{array}{c}0 \\
(0 \%)\end{array}$ & $\begin{array}{c}2 \\
(66.66 \%)\end{array}$ & $\begin{array}{c}1 \\
(33.33 \%)\end{array}$ & $\begin{array}{c}0 \\
(0 \%)\end{array}$ & $\begin{array}{c}0 \\
(0 \%)\end{array}$ & $\begin{array}{c}0 \\
(0 \%)\end{array}$ \\
\hline $\begin{array}{l}\text { Operación } \\
\text { Galaxia }\end{array}$ & $\begin{array}{c}1 \\
(25 \%) \\
\end{array}$ & $\begin{array}{c}1 \\
(25 \%) \\
\end{array}$ & $\begin{array}{c}2 \\
(50 \%) \\
\end{array}$ & $\begin{array}{c}0 \\
(0 \%) \\
\end{array}$ & $\begin{array}{c}0 \\
(0 \%) \\
\end{array}$ & $\begin{array}{c}0 \\
(0 \%) \\
\end{array}$ & $\begin{array}{c}0 \\
(0 \%) \\
\end{array}$ & $\begin{array}{c}0 \\
(0 \%) \\
\end{array}$ & $\begin{array}{c}0 \\
(0 \%) \\
\end{array}$ \\
\hline $\begin{array}{l}\text { Referéndum } \\
\text { Constitución. }\end{array}$ & $\begin{array}{c}3 \\
(27.27 \%)\end{array}$ & $\begin{array}{c}6 \\
(54.54 \%)\end{array}$ & $\begin{array}{c}2 \\
(18.18 \%)\end{array}$ & $\begin{array}{c}3 \\
(33.33 \%)\end{array}$ & $\begin{array}{c}6 \\
(66.66 \%)\end{array}$ & $\begin{array}{c}0 \\
(0 \%)\end{array}$ & $\begin{array}{c}3 \\
(42.85 \%)\end{array}$ & $\begin{array}{c}4 \\
(57.14 \%)\end{array}$ & $\begin{array}{c}0 \\
(0 \%)\end{array}$ \\
\hline TOTAL & $78,47 \%$ & $13,67 \%$ & $7,57 \%$ & $56,81 \%$ & $30,06 \%$ & $13,11 \%$ & $75,71 \%$ & $14,65 \%$ & $9,61 \%$ \\
\hline
\end{tabular}

Fuente: Elaboración propia.

Y, si bien es cierto que en el editorial se aprecia un elevado grado de apoyo al Ejecutivo, el panorama que ofrecen los datos referidos a las columnas y los artículos de opinión diverge de forma considerable con respecto a aquélla. De esta forma, el porcentaje de afinidad entre las columnas y Gobierno alcanza el 56,81\%, concentrándose hasta el $43,17 \%$ en los parámetros de tratamiento neutro y negativo. Y en el último tipo de unidades de análisis, los artículos de opinión, el posicionamiento a favor del Gobierno se sitúa en el $70,30 \%$, con un $24,26 \%$ de posicionamiento neutro y negativo. Con esto, queda constancia de que el género que concentra mayor discrepancia con respecto a los intereses del Gobierno son las columnas, que son los colaboradores con una relación asidua con el medio. Si bien es cierto que son los ítems más numerosos de la muestra. Veamos ahora cómo evolucionó el posicionamiento de las piezas de opinión con respecto al Gobierno durante los turnos de Arias, Suárez y UCD al frente del Ejecutivo.

\subsection{Durante el Gobierno Arias (1974-1976)}

La crítica hacia el Gobierno existente en este primer período se concentra en la huelga general, mientras que en el resto de hitos destaca la presencia del posicionamiento positivo o neutro en su defecto.

De esta forma, durante la huelga general el editorial del diario destacaba la gestión del Gobierno Arias, asegurando que los paros laborales se debían a la instigación por parte del ilegal Partido Comunista (3) que estaba intentado desestabilizar al país. Lo contradecía la columna de Fernando Ónega, en la que se acusaba al Ejecutivo de falta de autoridad, responsabilizándolo de las constantes movilizaciones que estaban teniendo lugar durante este tiempo (4). El autor también arremetió contra el Gobierno Arias en su columna, al que acusó de estar cerrando las puertas que llevaban a la democracia española con su afán inmovilista de no reconocer a los partidos políticos (5).

Por lo tanto, y pesar de lo discreto de la cifra del posicionamiento negativo con respecto al Gobierno Arias, la presencia de discursos contrarios al Ejecutivo y su 
gestión durante este período contradice a Redero y García (1991), demostrando que el diario nodriza, al contener discursos contrarios al poder, no fue un órgano de propaganda durante el Gobierno Arias, tal y como ellos sostenían.

\subsection{Durante el Gobierno Suárez (1976-1977)}

Tampoco fue órgano de propaganda del Gobierno Suárez, durante el que también se dieron cita distintos discursos con respecto al poder. Así, tras la llegada del presidente al Gobierno, se le consideró como un español de la nueva generación - "la que no habia vivido la Guerra Civil"'- asegurando que el tándem Rey Juan Carlos- Adolfo Suárez suponía el primer paso para la democracia (6).

Y si bien le dieron una cálida bienvenida al presidente en julio de 1976, pronto comenzaron las críticas. Así, durante el referéndum para la ley de la Reforma Política en diciembre de 1976, Pedro Rodríguez criticó al Ejecutivo por querer llevar al pueblo español a la democracia quiérala éste o no (7), mientras Felipe Gutiérrez acusaba al Gobierno Suárez de rupturista al menos, a nivel económico- al intentar implantar el liberalismo económico, alejándose así del proteccionismo que se había instaurado durante la dictadura, y al cual defendía (8).

Sin embargo, no todo fueron críticas. En el extremo opuesto, Fernando Ónega alababa la autoridad y la serenidad del Gabinete en la gestión de la ley para la reforma política (9). Conectaba a la perfección con lo sostenido por el editorial del diario que apostaba por votar favorablemente a la consulta, ya que el voto contrario a la misma suponía la falta de lealtad a un pueblo que quería elegir libremente a sus representantes, participando activamente en la vida política del país (10), y atentaba contra la autoridad y el sentido común que estaba demostrando el Gobierno (11) desde el cual se estaba afrontando de forma muy serena el secuestro del presidente del Consejo de Estado, Oriol y Urquijo.

Finalmente, la población española refrendó la Ley de la Reforma Política en diciembre de 1976, y 1977 comenzó con una sangrienta oleada de violencia política, que se saldó con la muerte de cinco abogados laboralistas en la Calle Atocha (Madrid) y varios agentes de las Fuerzas del Orden Público en diversos puntos del país.

Ante esta situación, las críticas en las páginas de opinión del diario hacia el Gobierno y su gestión no sólo aumentaron, sino que se endurecieron. De esta forma, el ex director de Arriba, Cristóbal Páez, acusó al Gobierno Suárez de tener en sus filas a personajes del franquismo (12) y de haber mantenido inalterable el ordenamiento jurídico de España, impidiendo así la evolución legislativa del país y, por tanto, perpetuando un sistema anquilosado en el régimen anterior (13). Para él, estos factores acompañados de una amplia "vacatio legis" durante la dictadura estaban provocando el aumento de atentados y secuestros.

El editorial presentaba el punto de vista opuesto y destacaba que, a pesar de la constante amenaza que suponía el terrorismo en esta época, el Gobierno estaba 
manteniendo la calma en el transcurso de una reforma política en la que la nota predominante estaba siendo la autoridad y el 'buen hacer' (14).

La misma disensión se produjo durante uno de los momentos de mayor convulsión de la transición: la legalización del Partido Comunista el Sábado Santo rojo. Entonces, el 25\% de las piezas publicadas arremetió contra el Gobierno, reprochándole que esta medida había hechos estragos en la bolsa (15). Entraban en contradicción con la línea editorial que la calificaba como 'decisión realista' que suponía un paso adelante en la democracia (16).

Y, siguiendo una línea de disensión similar, durante las elecciones legislativas se acusó al presidente Suárez de presentarse a los comicios en una clara situación de ventaja con respecto al resto de candidatos ("sentado en su columna dórica") al no haber disuelto las cámaras (17). Ésta entraba en contradicción con aquellas alabanzas a su gestión y su autoridad, a las que consideraban la razón principal por la que se pudo celebrar la consulta de diciembre de 1976, que fue el germen de la pluralidad política presente en las elecciones legislativas de 1977 (18).

La contrariedad aumentó a medida que se acercaba el día de las elecciones $(15 \mathrm{~J})$. De esta forma, mientras unos textos de opinión instaban a votar a los conservadores criticando a UCD (19) por la legalización del PCE, otros criticaban al Gabinete por su cercanía a la derecha, acusándolo de ser el residuo del Partido Único y de mantener a personalidades del franquismo aún en sus filas (20).

De esta forma, la confluencia de estos distintos discursos demuestra la presencia de posicionamientos contrarios al poder durante el turno de Suárez al frente del Ejecutivo, lo que supone que el diario Arriba no fue un órgano de propaganda del Gobierno. Además, queda constancia de que, a medida que transcurre el proceso de cambio de régimen, la presencia de las críticas contra el Gobierno van in crescendo. Esto, a su vez, constituye un proceso evolutivo que constata que, durante el Gobierno Suárez, las voces críticas contra su gestión aumentaron de forma considerable, contradiciendo así las versiones oficiales sobre la inmovilidad de este tipo de prensa durante la etapa seleccionada para el estudio.

\subsection{Durante el Gobierno de la UCD (1977-1981)}

Fue durante el Gobierno de la UCD y, sobre todo, a raíz de la propuesta de éste de liquidar la prensa estatal, cuando el 'diario nodriza' experimenta un punto de inflexión en su evolución. En este último período, la cabecera retira definitivamente su favor al Gobierno de la UCD, virando hacia la izquierda, sobre todo hacia el PSOE, que mostró explícitamente su apoyo a la prensa oficial, afirmando que otras democracias contaban con prensa estatal y ello no suponía restarle espíritu crítico.

Así, por un lado, observamos que el editorial del diario acusaba al "patrón de la prensa oficial" (el Gobierno) de haberse servido de la misma para ganar las elecciones legislativas de 1977, abandonándola después a su suerte, calificándola de antidemocrática (21). En la misma línea, Carlos Rodríguez destacaba que esta decisión por 
parte del Gobierno Suárez era decepcionante (22), instándole a recapacitar. El mismo autor, bajo su seudónimo Ricardo Blom, aprovechó las declaraciones de Santiago Carrillo, líder del Partido Comunista, para reprobar los Pactos de la Moncloa al considerar que suponían más sacrificios que beneficios para el pueblo (23).

En el mismo tono de crítica, Manuel Blanco Tobío arremetió duramente contra el Gobierno Suárez considerando que había muchos países que disponían de prensa estatal y no por ello eran menos democráticos. Profundizaba en su crítica afirmando que el Ejecutivo intentaba demostrar un espíritu democrático al proponer la desaparición de la que fue órgano de propaganda del franquismo, cuando tenía en sus filas a muchos de los personajes del régimen anterior (como por ejemplo, Álvarez de Miranda), lo que lo inhabilitaba como Gobierno democrático (24).

Es, por tanto, a partir de la propuesta gubernamental de cierre de la cadena de prensa estatal, cuando el diario Arriba emprendió una estrategia de desprestigio del Gobierno. Para ello, comenzó a pedir la disolución de las cámaras y la celebración de unas elecciones legislativas que llevaran al PSOE al Gobierno (25), al que perfilaba como alternativa recomendable a la UCD, en el Ejecutivo desde octubre de 1977.

Esta estrategia se reforzó a partir de octubre de 1978, con la aprobación del texto constitucional, cuando se aprecia un aumento considerable de las críticas con respecto al Gobierno, al que se acusa de haber cometido muchos e imperdonables errores en la gestión del país. Asimismo, se le acusaba de estar retrasando de forma irresponsable la llegada de la democracia al país.

En esta misma línea, la ausencia injustificada de tres ucedistas (dos en el Congreso y uno en el Senado) en el momento de la votación del texto constitucional sirvieron a Carlos Rodríguez para calificar a la UCD como obstáculo en el camino hacia la democracia que había emprendido el país tras la muerte de Franco, destacando que era necesario un cambio en el Gobierno que supusiera la llegada del PSOE al mismo, equiparándonos así a las democracias europeas (26). Más dura fue aún Raquel Heredia, quien acusó al Gobierno de mantener en sus filas a Álvarez de Miranda (diputado ucedista) (27), al que acusaba de aprovecharse de su relación con el régimen franquista para mantener sus privilegios durante la transición.

Esta oleada de críticas hacia el Ejecutivo de la UCD, en aumento desde octubre de 1977, se redujo en noviembre de 1978 con la operación Galaxia. Y es que, ante el intento de golpe de estado, Arriba pretendió templar a la población llamando a la calma desde sus páginas y destacando la gran labor del Ministro de Defensa, Gutiérrez Mellado, que había servido para frustrar el intento de golpe militar mientras Suárez y el Rey se encontraban fuera del país. Sin embargo, se mantiene la campaña de desprestigio y desgaste del Gobierno, urgiendo a la disolución de las Cámaras y la celebración de las elecciones (28). Por lo que las únicas alabanzas hacia el Gobierno que se encuentran en este hito se centran en la figura del Ministro de Defensa.

Finalmente, en el referéndum de la Constitución de 1978, podemos constatar que la evolución del diario, cuya desavenencia con el Gobierno venía desde los Pactos 
de la Moncloa, es considerable. Por un lado, los textos no agradecen (29) a Suárez la gestión política que ha llevado a la Constitución (como sí lo hicieran por ejemplo, en la Ley para la Reforma Política) sino que se centraron en la descripción de la Constitución (30) y la incitación al voto favorable (31), adoptando un tono mayoritariamente neutro (32). Y, por el otro, se mantiene la exigencia de disolución de las Cortes y la celebración de elecciones legislativas (33).

Por lo tanto, al final del periodo de estudio, el tono de la mayor parte de los textos de opinión publicados en Arriba con respecto al Gobierno y su gestión se ha neutralizado, aumentando considerablemente las críticas contra él a partir de octubre de 1977 (propuesta de liquidación de los MCSE) y sobre todo a partir de octubre del año siguiente. Entonces, se considera al Ejecutivo de la UCD como un parapeto para la democracia en España por su cercanía a la derecha. Finalmente, la presencia de apoyo al Gobierno y su gestión son muy discretas ya al final del período de estudio (diciembre de 1978).

De esta forma, la evolución que el diario Arriba experimenta durante la transición, demostrada a través del análisis contenido cualitativo aplicado a la muestra estudiada en este trabajo, contradice a Montabes Pereira (1989), quien sostenía que la prensa oficial mantuvo su función propagandística durante el proceso de cambio de régimen. Asimismo, las diferencias discursivas existentes entre los editoriales, los artículos y las columnas de opinión demuestran que, tal y como apuntaban Villalobos (2010) y López Hidalgo (2012), los artículos y las columnas de opinión pueden diferir de forma considerable de lo sostenido por el editorial y, por lo tanto, son los garantes de la pluralidad de opinión presente en este diario.

Por tanto, podemos afirmar que el diario Arriba no fue un órgano de propaganda del Gobierno durante la transición española (1975-1978), sino que acogió distintas ideologías en este período y que, a su vez, se tradujeron en distintos discursos con respecto al Gobierno y su gestión (Hipótesis 1). Este hecho contribuyó de forma muy considerable a la evolución del posicionamiento que las piezas de opinión tuvieron con respecto al Ejecutivo y su gestión durante la transición, pasando de un apoyo mayoritario a un tono más neutro $y$, en un porcentaje muy considerable, crítico contra el mismo (hipótesis 2). Y, finalmente, esto le llevó a abandonar la función propagandística que le había sido encomendada durante la dictadura para garantizar el continuismo del régimen (hipótesis 3).

Una vez expuestos los resultados y validadas las hipótesis del presente trabajo, procedemos a presentar las conclusiones a las que hemos llegado en este estudio.

\section{Conclusiones}

El diario Arriba no fue un órgano de propaganda del Gobierno durante la transición. Lo demuestra la confluencia de distintos discursos dentro de sus páginas de 
opinión, lo que permite a su vez una pluralidad de puntos de vista sobre el Ejecutivo y su gestión que demuestran que el diario nodriza de la antigua cadena de Prensa y Radio del Movimiento acogió, durante el cambio de régimen (1975-1978), una considerable pluralidad de opinión imprevisible en una prensa de este tipo -que había estado al servicio del poder como órgano de propaganda- en un estado aún autoritario, y en transición hacia la democracia.

Por otro lado, los datos obtenidos demuestran la existencia de diversos discursos dentro las páginas de opinión del diario gracias a los distintos puntos de vista que, sobre la realidad, aportan editoriales, artículos y columnas de opinión. Tal y como se ha constatado en esta investigación, estas tres unidades de análisis no mantienen un discurso único y unificado con respecto al Gobierno sino que, por el contrario, reflejan distintos discursos, a veces, contrarios entre sí dentro de las páginas de opinión del periódico. De esta forma, hemos constatado que los artículos y las columnas de opinión publicados en este periódico durante la transición se erigieron como garantes de la pluralidad de opinión dentro del diario. Esto supone que el diario Arriba no difundió un discurso unificado con respecto al Ejecutivo, lo que es un requisito sine qua non para ser órgano de propaganda del mismo.

No solo eso, sino que el diario Arriba emprendió ataques directos contra el Ejecutivo, y por lo tanto, fue abandonando progresivamente su función como órgano de propaganda del poder durante este período. De esta forma, la cabecera retiró su apoyo al Ejecutivo a raíz de la negociación de los Pactos de la Moncloa, cuando el Gobierno de la UCD propuso la desaparición de la Prensa del Estado al considerarla antidemocrática. Asimismo, emprendió una campaña de desgaste contra el Ejecutivo a partir de la aprobación del texto constitucional que perseguía la disolución de las cámaras y la celebración de elecciones legislativas tras el referéndum.

A partir de entonces, Arriba comenzó a posicionarse en tono neutro hacia el Ejecutivo y su gestión, trasladando su favor a la fuerza mayoritaria de la oposición (PSOE), que había rechazado la propuesta de liquidación de la prensa estatal formulada por el Gobierno. Y, para argumentar su posición, la cabecera comenzó a presentar al PSOE como alternativa deseable a la UCD en el Gobierno. Sólo así se podría equiparar al país con el resto de democracias europeas.

De esta forma, se puede afirmar que los textos de opinión publicados en el diario Arriba evolucionaron en su posicionamiento con respecto al Gobierno durante la transición. Pasó, así, de ser un periódico pro gobierno, a adoptar un tono neutro y a veces contrario al mismo, sobre todo en los últimos períodos analizados en esta investigación, virando hacia el PSOE, y abandonando, por tanto, su función propagandística, lo que le permitió asumir su rol de agente político durante la transición. 


\section{Referencias bibliográficas}

ALFÉREZ, A. (1986). Cuarto poder en España: la prensa desde la Ley Fraga 1966. Espulgues de Llobregat: Plaza \& Janés.

CASTRO TORRES, C. (2010). La Prensa en la transición española 1966/1982. Madrid: Alianza Ensayo.

BARRERA, C. (1995). Sin mordaza: veinte años de prensa en democracia. Madrid: Temas de hoy.

BERELSON, Bernard (1952) Content Analysis En: Handbook of Social Psychology, Vol I. Nueva-York.

BORRAT, H. (1989). El periódico actor político. Barcelona: Gustavo Gili.

FUSI, J. P. (1996). "El desarrollo autonómico". En TUSELL, J.; SOTO, Á. Historia de Transición, 1975-1986. Madrid: Alianza Universidad.

GUILLAMET, J. (2002). "Factores de progreso y atraso en la evolución histórica del periodismo. El franquismo". En GARCÍA GALINDO, J. A.; GUTIÉRREZ LOZANO, J.; SÁNCHEZ ALARCÓN, I. (eds.). La comunicación social durante el franquismo. Málaga: Centro de Ediciones de la Diputación Provincial de Málaga.

KRIPPENDORFF, K. (1982). Content Analysis; An Introduction to its Methodology. Beverly Hills, CA: Sage.

(2012). Content Analysis; An Introduction to its Methodology, 3rd Edition. Thousand Oaks, CA: Sage.

LANDRY, R. (1998). "L'analyse de contenu". En: Recherche Sociale. De la problemátique à la collecte des données. Benoit Gauthier (Editor). Sillery, Presses de l'Université du Québec. p. 329-356.

LÓPEZ HIDALGO, A. (2012). La columna: periodismo y literatura en un género plural. Zamora: Comunicación Social.

MARTÍN VIVALDI, G. (1987). Géneros periodísticos. Madrid: Paraninfo.

MAURI DE LOS RÍOS, M. (2010). Funció i evolució de la prensa de Barcelona durant la transició democrática (1975-1978). Tesis Doctoral. Barcelona: Universitat Pompeu Fabra.

MENESES D. (2008). Noticias sobre la prensa: imagen propia en la transición democrática. Madrid: Fragua.

MONTABES PEREIRA, J. (1986). La Prensa del Movimiento: Estudio analítico de la Prensa del Estado durante la Transición Política española 1975-1978. Tesis Doctoral. Granada: Universidad de Granada.

(1989). La prensa del estado durante la transición política española. Madrid: Siglo XXI de España de Editores.

PEÑA MARÍN, C. (1980). El discurso político en la prensa madrileña del franquismo. Madrid: Bulzoni.

PINEDA CACHERO, A. (2001). "El modelo de propaganda de Noam Chomsky: medios mainstream y control del pensamiento". En ÁMBITOS, $\mathrm{n}^{\circ}$ 6, Sevilla: Universidad de Sevilla, p. 191-210.

(2006). Elementos para una teoría comunicacional de la propaganda. Sevilla: Ediciones Alfar. 
POSTOUTENKO, K. J. (2010). Soviet culture: codes and messages. Verlag Otto Sagner, Bielfeld.

POWELL C. T. (1991). El piloto del cambio: el rey, la monarquía y la transición a la democracia. Madrid: Editorial Planeta.

SEOANE, M. C.; SAIZ, M. D. (2007). Historia del Periodismo en España 3. El Siglo XX: 1896-1936. Madrid: Alianza Editorial.

SOTO, Á. (1998). La transición a la democracia. Madrid: Alianza Editorial.

TUSELL, J. (1991). La transición española a la democracia. Madrid: Colección Biblioteca Historia 16.

VILLALOBOS SALAS, C. (2010): "El articulismo de opinión como fuente para la investigación histórica: el ejemplo del franquismo". En Espéculo: Revista de Estudios Literarios, $\mathrm{n}^{\circ}$ 47, p. 29.

\section{Notas}

1 En los procesos electorales y la celebración de referéndums producidos entre 1975 y 1978 , la prensa abordaría el tema de forma muy extensa en el tiempo. En el caso del Referéndum para la Reforma política, desde octubre hasta diciembre de1976; en las elecciones legislativas de 1977, desde abril (convocatoria) hasta finales de junio de 1977; y, en el caso del referéndum de la Constitución de 1978, desde el 1 de noviembre hasta finales de diciembre. El seguimiento de estos tres períodos íntegros constituirían 180 ediciones por diario, lo que sería una muestra inabarcable para este trabajo. Es por ello que, para la selección del contenido referente a estos momentos históricos, se ha atendido a lo que sostiene Paul Lazarsfeld (1953) en su análisis sobre las presidenciales americanas. La técnica que utilizó para su estudio fue la encuesta mensual a diferentes grupos representativos en diferentes momentos. Es decir, la población (600 personas) fue entrevistada siete veces en distintos puntos de la campaña electoral. La última vez fue la semana antes de las elecciones. El autor concluyó entonces que los grupos de electores se homogeneizan a medida que se acerca el día de las elecciones y que, en la última semana de la campaña, los propagandistas dirigieron sus esfuerzos a los 'indecisos' (1953: 407). Es por ello que, atendiendo a las conclusiones del estudio anteriormente explicado, en el presente trabajo hemos abordado los períodos 4,7 y 12 de la forma expuesta en la tabla 1.

2 Los períodos 10 y 11, ambos contenidos en noviembre de 1978, están separados por no constituir una unidad temporal. Es decir, porque entre el 2 y el 18 de noviembre no se produce un seguimiento temático de ninguno de los temas seleccionados para este trabajo.

3 Se entiende por propio en este trabajo a la existencia de una relación contractual directa entre el periodista y el periódico durante el período de tiempo que se explicita entre paréntesis.

4 Fuente: www.psoe.es/ambito/fuencarral/docs/index.do?action=Print\&id=426696 (Consultado el 14 de enero 2013).

5 El autor dice en el artículo "Anatomía de una matanza", publicado en Arriba, el 30-01-1977, pp. 6 y $7:$ "[...] mientras a los falangistas nos dispersaba el viento para siempre".

6 Fue director de prensa de la Presidencia del Gobierno con Adolfo Suárez.

7 Cuando Ónega abandona el diario, Cavero Jáñez ocupa su lugar en la redacción de las columnas pro ucedistas que antes publicaba aquél. 
8 Fuente: www.infonacional.com/72012/02/ha-fallecido-el-periodista-y-escritor.html (Consultado el 14 de enero de 2013). Se trata de una página web hecha por falangistas.

\section{Referencias hemerográficas}

(1) Únicamente se han especificado los datos referentes a la ideología o inclinación ideológica de las personas que formaban parte del Consejo Editorial, u órgano de toma de decisiones del diario, cuando han sido obtenidas de fuentes fiables, como su militancia oficial y pública en un partido político o su auto-calificación como tal en alguna entrevista realizada en medios de comunicación.

(2) Para León Gross (1996), articulismo y columnismo son dos géneros de opinión a medio camino entre el periodismo y la literatura, por lo que su uso como fuente para el estudio de la prensa ha sido obviado tradicionalmente.

(3) Arriba, 05-03-1976, p. 2: *Una huelga, seis mil pesetas

(4) Arriba, 04-03-1976, pp. 1 y 2. Fernando Ónega: El Péndulo.

(5) Arriba, 07-03-1976, p. 2. Fernando Ónega: El Péndulo.

(6) Arriba, 12-06-1976, p. 7. Ricardo Blom: Adolfo Suárez.

(7) Arriba, 14-12-1976, p. 2. P.R.: Nombres propios: Vino tinto.

(8) Arriba, 15-12-1976, p. 6. Felipe Gutiérrez Benito: Referéndum y economía.

(9) Arriba, 16-12-1976, p. 2. Fernando Ónega: El Péndulo

(10) Arriba, 14-12-1976, pp. 5 y 7. Las razones del $<<S i ́>>$.

(11) Arriba, 16-12-1976, p. 2. Fernando Ónega: El Péndulo

(12) Arriba, 27-01-1977, p. 7. Cristóbal Páez: Observatorio, Los nidos de la violencia.

(13) Arriba, 29-01-1977, p. 7. Cristóbal Páez: Observatorio.

(14) Arriba, 28-01-1977, p. 7. *La situación.

(15) Arriba, 14-04-1977, p. 6: Marzo, ventoso...

(16) Arriba, 10-04-1977, p. 2. *Una decisión realista.

(17) Arriba, 07-06-1977, p. 7. Félix Ortega: El Candidato Suárez.

(18) Arriba, 08-06-1977, p. 7. José Cavero: Cambiar será inevitable.

(19) Arriba, 14-06-1977, p. 12. Lavern: Dicho y oído.

(20) Arriba, 15-06-1977, p. 5. Antonio Salcedo: La Situación.

(21) Arriba, 19-10-1977, p. 7. Ética social, trabajo y profesión.

(22) Arriba, 19-10-1977, p. 8. Carlos Rodríguez: La Política y los días.

(23) Arriba, 20-10-1977, p. 6. Ricardo Blom: Política.

(24) Arriba, 26-10-1977, p. 7. Manuel Blanco Tobío: Un servicio público.

(25) Arriba, 01-11-1978, p. 7: *Un Parlamento liberado.

(26) Arriba, 01-11-1978, p. 10. Carlos Rodríguez: La política y los días. 
(27) Arriba, 01-11-1978, pp. 2 y 3. Raquel Heredia: Columna, Historia de pasillos.

(28) Arriba, 19-11-1978, p. 7: *El precio de las elecciones.

(29) Arriba, 03-12-1978, p. 7: *Razones para el $<<s i>>$.

(30) Arriba, 07-12-1978, p. 1. *Un marco para el progreso.

(31) Arriba, 07-12-1977, p. 12. Carlos Rodríguez: La Política y los días: Unidos para ganar el futuro.

(32) Arriba, 03-12-1978, p. 8. Carlos Rodríguez: La Política y los Días: Construir la nación.

(32) Arriba, 09-12-1977, p. 12. Carlos Rodríguez: La Política y los días.

\section{Las autoras}

Jezabel Martínez Fábregas. Licenciada en Comunicación Audiovisual (2007) y Periodismo (2009). Doctora en Periodismo por la Universidad de Sevilla (2014). Investigadora del Grupo de Investigación GREHCCO (Estructura, Historia y Contenidos de la Comunicación). Investigadora en el Proyecto de Investigación "El papel de la prensa diaria en la transición democrática. Cobertura informativa y comportamiento político de diarios y periodistas", referencia CSO2012-36774, del Plan Nacional I+D 2013-2015 CSO 2012 36774, dirigido por el Catedrático Dr. Jaume Guillamet Lloveras (Universitat Pompeu Fabra). Líneas de investigación: Historia del Periodismo Español, Economía Política de la Comunicación, Propaganda.

Lorena R. Romero Domínguez. Doctora en Periodismo (2007) y profesora en la Facultad de Comunicación de la Universidad de Sevilla. Miembro del Grupo de Investigación "Medios, políticas de comunicación y democracia en la Unión Europea", y de las sociedades científicas Ulepicc-España, Sociedad Latina de Comunicación Social y Asociación de Historiadores de la Comunicación. Ha sido profesora invitada en las siguientes universidades: Johannes-Gutenberg Mainz Universität (Alemania), Cardiff University (País de Gales), Konstanz Universität (Alemania), Humboldt Universität zu Berlin (Alemania). Ha publicado, entre otras, en las siguientes revistas indexadas: International Journal of Iberian Studies, Estudios sobre el Mensaje Periodístico (UCM), Revista de Humanidades (UNED), Ámbitos, Revista Internacional de Comunicación (US), Trípodos, Revista Latina de Comunicación Social (ULL), Comunicación y Sociedad (UNAV), El Argonauta Español. Líneas de investigación: Historia del Periodismo Español, Economía Política de la Comunicación. 